\title{
AVALIAC̃̃̃O QUÍMICA DE GELÉIAS DE MANGA FORMULADAS COM DIFERENTES NÍVEIS DE CASCAS EM SUBSTITUIÇÃO À POLPA
}

\author{
Chemical evaluation of mango (Mangifera indica $L$ ) jams formulated with different \\ levels of peels in substitution to pulp
}

\author{
Clarissa Damiani' ${ }^{1}$, Eduardo Valério de Barros Vilas Boas², Manoel Soares Soares Junior³, \\ Marcio Caliari ${ }^{4}$, Maria do Livramento de Paula ${ }^{5}$, Eduardo Ramirez Asquieri ${ }^{6}$
}

\begin{abstract}
RESUMO
Objetivou-se, neste estudo, avaliar a qualidade de geléias formuladas com níveis de $0 \%, 25 \%, 50 \%, 75 \%$ e $100 \%$ de cascas em substituição à polpa de manga (Mangifera indica L. cv. Haden). Os critérios de qualidade utilizados foram os teores de umidade, cinzas, proteínas, lipídios, carboidratos totais, açúcares totais, açúcares redutores, sacarose, vitamina C, fibra insolúvel, pectina, acidez titulável e sólidos solúveis nas polpas e cascas das mangas e nos diferentes tratamentos. Observou-se que nos tratamentos com substituição da polpa por cascas encontraram-se teores significativamente maiores de proteínas, fibras insolúveis e sacarose e menores valores calóricos, acidez titulável, carboidratos totais e açúcares totais em relação ao controle. Os tratamentos foram semelhantes em relação ao teor de vitamina $\mathrm{C}$ e sólidos solúveis. Com a elevação dos níveis de cascas em substituição à polpa observou-se aumento do teor de cinzas, fibras insolúveis e sacarose e redução dos açúcares redutores. Concluiu-se que a substituição parcial ou total de polpa por cascas de manga na formulação melhora o valor nutricional e funcional das geléias apesar da diminuição do valor calórico, com benefícios econômicos e ambientais.
\end{abstract}

Termos para indexação: Mangifera indica, resíduo, composição química, geléia.

\section{ABSTRACT}

The aim of this study was to evaluate the quality of jams formulated with peel levels of $0 \%, 25 \%, 50 \%, 75 \%$ and $100 \%$ in substitution to mango pulp (Mangifera indica L. cv. Haden). The quality criteria were moisture, ashes, proteins, fat, total carbohydrate, total sugars, reducing sugars, sucrose, vitamin $\mathrm{C}$, insoluble fiber, pectin, titrable fruit acidity, soluble solids contents and $\mathrm{pH}$ in the mango pulp, mango peels and different treatments. It was observed that in the treatments with substitution of pulp by peels, the contents of proteins, insoluble fiber and sucrose were significantly higher than the control. The caloric values, titrable fruit acidity, total carbohydrate and total sugars were lower than the control. There was no significant difference among the treatments regarding vitamin $\mathrm{C}$ and soluble solids contents. With the increase of levels of peels in substitution to pulp it was observed an increase in ashes, insoluble fiber and sucrose and decrease in reducing sugar contents. As a conclusion, the partial or total substitution of pulp by mango peels in the formulation improved the nutritional and functional values of the jams, in addition of a decrease in the caloric value, with economic and environmental advantages.

Index terms: Mangifera indica, residue, chemical composition, jam.

(Recebido em 8 de março de 2007 e aprovado em 4 de junho de 2008)

\section{INTRODUÇÃO}

No mercado nacional, a manga é comercializada quase exclusivamente na forma in natura, sendo a cultivar Haden a segunda mais consumida, ou na forma industrializada, como sucos integrais e polpas congeladas. A polpa pode ser empregada na elaboração de doces, geléias, néctares, sorvetes, sucos puros ou misturas, licores e outros produtos (ARAÚJO, 2004). A importância de frutas processadas vem crescendo, em virtude das facilidades proporcionadas pelos produtos já prontos para o consumo, do maior número de pessoas morando sozinhas e da melhoria da qualidade dos produtos ofertados (FERRAZ et al., 2002).

\footnotetext{
'Engenheira de Alimentos - Universidade Federal de Goiás/UFG - Rodovia Estrada Goiânia - Km 0 - Campus Samambaia - Nova Veneza - Goiânia, GO 74001-970 - damianiclarissa@hotmail.com

Engenheiro Agrônomo - Departamento de Ciência dos Alimentos/DCA - Universidade Federal de Lavras/UFLA - Cx. P. 3037 - $37200-000$ - Lavras, MG evbvboas@ufla.br

${ }^{3}$ Engenheiro Agrônomo - Universidade Federal de Goiás/UFG - Rodovia Estrada Goiânia - Km 0 - Campus Samambaia - Nova Veneza - Goiânia, GO 74001-970 - manoel@agro.ufg.br

${ }^{4}$ Engenheiro Químico - Universidade Federal de Goiás/UFG - Rodovia Estrada Goiânia - Km 0 - Campus Samambaia - Nova Veneza - Goiânia, GO 74001-970 - macaliari@ig.com.br

${ }^{5}$ Engenheira de Alimentos - Universidade Católica de Goiás - Avenida Universitária, 1440 - Setor Universitário - 74604-220 - Goiânia, GO lilidepaula@hotmail.com

${ }^{6}$ Engenheiro de Alimentos - Universidade Federal de Goiás/UFG - Praça Universitária com 1를 Avenida, s/n - 74604-220 - Goiânia, GO - asquieri@farmacia.br
} 
É importante destacar que, no mercado brasileiro de frutas in natura, é elevado o porcentual de perdas. Segundo Chitarra \& Chitarra (2005), as perdas com manga chegam a $27,43 \%$, decorrentes de falhas na fase de produção, colheita fora de época, tempo de exposição prolongado no varejo, preços desfavoráveis ao produtor e falta de orientação de mercado.

A industrialização da manga, inclusive da casca, pode ser uma alternativa para atenuar as perdas pelo aproveitamento das frutas fora do padrão de comercialização in natura, para abrandar a geração de resíduos orgânicos sólidos e produzir alimentos saudáveis pela incorporação de fibras e compostos com atividade antioxidante oriundos das cascas. Essas cascas são constituídas por água, proteínas e carboidratos (entre os quais as fibras), o que possibilita o seu aproveitamento na fabricação de doces, pães, biscoitos, geléias, etc.

Objetivou-se, neste trabalho, avaliar as características químicas de geléias de manga (Mangifera indica L) cv. Haden elaboradas com diferentes níveis de substituição de polpa por cascas.

\section{MATERIALE MÉTODOS}

Mangas (Mangifera indica L. cv. Haden), safra 2006, provenientes da Fazenda Santana, região do Vale do Rio São Francisco, BA, foram adquiridas no mercado local de Goiânia, GO, encontrando-se pré-selecionadas, embaladas em caixas de papelão e sob refrigeração. As frutas foram levadas para o Laboratório de Tecnologia de Frutas e Hortaliças da Universidade Católica de Goiás (UCG), onde foram selecionadas aquelas cujas cores foram classificadas nos níveis quatro (mais de $60 \%$ de cor amarela e menos de $30 \%$ de cor laranja) e cinco (mais de $90 \%$ de cor laranja), de acordo com a Deutsche Gesellschaft Fur Technische Zusammenarbett (1992). As mangas escolhidas foram lavadas com detergente neutro, enxaguadas em água corrente, sanificadas com hipoclorito de sódio $(\mathrm{NaClO})$ a $200 \mathrm{ppm}$ por 15 minutos, descascadas e despolpadas manualmente com auxílio de facas. A polpa das mangas foi triturada em liquidificador industrial em aço inox (25 litros de capacidade) e levada a uma despolpadeira dupla horizontal com peneiras de $1 \mathrm{~mm}$ e $0,5 \mathrm{~mm}$, para remoção do material fibroso. As cascas foram cozidas por vinte minutos, em concentrador a vapor, encamisado aberto, trituradas em liquidificador industrial em aço inox e levadas a uma despolpadeira dupla horizontal, com peneiras de 1 $\mathrm{mm}$ e $0,5 \mathrm{~mm}$, para remoção de partículas grandes. Esse processo foi realizado por duas vezes para total homogeneização do suco.

As geléias de manga cv. Haden foram formuladas com diferentes níveis de cascas em substituição à polpa (Tabela 1), sendo processadas de forma inteiramente casualisada, utilizando-se o método descrito em Lopes (1985).

Para a elaboração dos tratamentos, primeiramente, mediu-se o teor de sólidos solúveis do suco da casca e/ou polpa da manga, de acordo com a formulação, e adicionouse água potável até redução do teor de sólidos solúveis a $20^{\circ}$ Brix. Em seguida, misturou-se um terço do açúcar e a solução foi levada para o concentrador equipado com pás misturadoras até o início da ebulição, momento no qual se adicionou mais um terço do açúcar previamente homogeneizado com a pectina. Após nova ebulição, inseriuse o restante do açúcar e esperou-se concentrar até $63^{\circ}$ Brix. Nesse instante, adicionou-se o acido cítrico diluído em um pouco de água potável para a redução do $\mathrm{pH}$ até aproximadamente 3,2 e concentrou-se até $65^{\circ}$ Brix. Para o envase da geléia a $85{ }^{\circ} \mathrm{C}$ utilizaram-se potes de vidro de $300 \mathrm{~g}$, previamente esterilizados. As embalagens foram colocadas no exaustor para formação de vácuo e, em seguida, viradas com as tampas para baixo por 5 minutos, resfriadas e acondicionadas em caixa de papelão à temperatura ambiente.

Tabela 1 - Massa (g) dos ingredientes que entraram nas geléias de manga formuladas com diferentes níveis de cascas em substituição à polpa (tratamentos). UCG, Goiânia, GO, 2006.

\begin{tabular}{cccccc}
\hline Tratamentos com & \multicolumn{3}{c}{ Ingredientes $(\mathrm{g})$} \\
\cline { 2 - 5 } $\begin{array}{c}\text { seus níveis de } \\
\text { substituição }\end{array}$ & Casca & Polpa & Açúcar & Pectina & Ácido Cítrico* \\
\hline $0 \%$ (controle) & 0,000 & 5000 & 5000 & 75 & 50 \\
$25 \%$ & 1250 & 3750 & 5000 & 125 & 26 \\
$50 \%$ & 2500 & 2500 & 5000 & 125 & 17 \\
$75 \%$ & 3750 & 1250 & 5000 & 50 & 30 \\
Geléia de casca & 5000 & 0,000 & 5000 & 125 & 16 \\
\hline
\end{tabular}

*quantidade necessária para que o suco atinja o pH de 3,2. 
As características químicas de quinze mangas in natura e dos diferentes tratamentos foram determinadas no Laboratório de Química e Bioquímica de Alimentos da Faculdade de Farmácia da Universidade Federal de Goiás (UFG). Os teores de umidade, cinzas e proteínas foram determinados segundo os métodos recomendados pelo Instituto Adolfo Lutz (BRASIL, 2005); os lipídios segundo Bligh \& Dyer (1959); os carboidratos totais conforme Dubois et al. (1956); e o valor calórico total foi estimado conforme os valores de conversão de Atwater, descritos em Wilson et al. (1982). Os açúcares redutores foram determinados, segundo o método de ADNS Acido Dinitrossalicílico (MILLER, 1959); a sacarose e os açúcares totais pelo método ADNS, com as modificações incorporadas por Silva et al. (2003); a vitamina C, segundo Miranda \& Battisti (2001); a fibra insolúvel pelo método de Scharrer \& Kurschner, descrito em Beythien \& Diemair (1963); a pectina, conforme a metodologia de Less (1969); a acidez titulável também segundo método descrito pelo Instituto Adolfo Lutz (BRASIL, 2005); e os sólidos solúveis conforme a AOAC (1995).

Para avaliação dos resultados das análises químicas das polpas e cascas das amostras de manga, calcularamse as médias, os desvios-padrão e os coeficientes de variação. Enquanto que, para os diferentes tratamentos, avaliaram-se os resultados através da análise de variância. Os modelos de regressões polinomiais foram selecionados com base na significância de teste de F de cada modelo testado e também pelo coeficiente de determinação, utilizando-se o programa SAS Institute (1996).

\section{RESULTADOS E DISCUSSÕES}

Os resultados médios das análises químicas da polpa e da casca das mangas estão apresentados na Tabela 2.

A casca apresentou maiores teores médios de cinzas, proteínas, lipídios, carboidratos totais, vitamina $\mathrm{C}$, fibra insolúvel e acidez titulável, no entanto, maiores teores de umidade, açúcares totais, açúcares redutores, sacarose, pectina e sólidos solúveis foram encontrados na polpa.

Estudo realizado por Gonçalves (1998) com diversas variedades de manga no sul de Minas Gerais reportou que a polpa da 'Haden' possuía, em média, 6,30 g $100 \mathrm{~g}^{-1}$ de

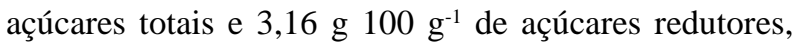
valores esses inferiores aos encontrados no presente trabalho, contudo, os teores de vitamina $\mathrm{C}\left(62,92 \mathrm{mg} 100 \mathrm{~g}^{-1}\right)$,

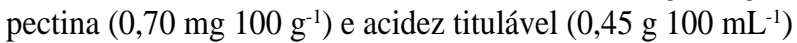
foram maiores. Já pesquisadores do USDA (1999), obtiveram em média para polpa da manga 'Haden' 81,7 g

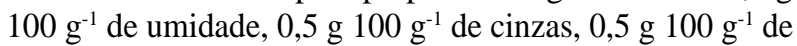

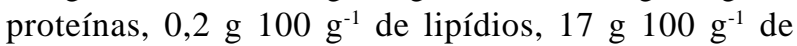
carboidratos totais e $27 \mathrm{mg} 100 \mathrm{~g}^{-1}$ de vitamina $\mathrm{C}$, valores muito próximos aos encontrados no presente trabalho.

Ajila et al. (2006) estudando os componentes disponíveis nas cascas de mangas maduras (variedades indianas) encontraram teores de umidade entre 72,5-75,25 g $100 \mathrm{~g}^{-1}$, de cinzas entre 1,3-1,6 g $100 \mathrm{~g}^{-1}$, de proteínas entre 1,8-2,1 g $10 \mathrm{~g}^{-1}$, de lipídios entre 2,2-2,3 g $100 \mathrm{~g}^{-1}$, de

Tabela 2 - Valores médios das características químicas da polpa e da casca das amostras de manga cv. Haden, com seus respectivos desvios-padrão e coeficientes de variação. UFG, Goiânia, GO, 2006.

\begin{tabular}{|c|c|c|}
\hline Característica Química & Polpa* & Casca* \\
\hline Umidade $\left({\left.\mathrm{g} 100 \mathrm{~g}^{-1}\right)}\right.$ & $81,98 \pm 0,25(0,31)$ & $77,41 \pm 0,15(0,20)$ \\
\hline 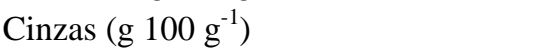 & $0,32 \pm 0,01(2,58)$ & $0,83 \pm 0,0,(1,19)$ \\
\hline Proteínas (g $\left.100 \mathrm{~g}^{-1}\right)$ & $0,71 \pm 0,01(1,48)$ & $1,29 \pm 0,02(1,51)$ \\
\hline Lipídios (g $\left.100 \mathrm{~g}^{-1}\right)$ & $0,32+0,01(1,73)$ & $0,91 \pm 0,02(2,07)$ \\
\hline Carboidratos totais $\left(\mathrm{g} 100 \mathrm{~g}^{-1}\right.$ ) & $16,67 \pm 0,06(0,40)$ & $19,56 \pm 0,06(0,30)$ \\
\hline Açúcares totais $\left(\mathrm{g} 100 \mathrm{~g}^{-1}\right)$ & $13,20 \pm 0,06(0,45)$ & $11,30+0,04(0,40)$ \\
\hline Açúcares redutores $\left(\mathrm{g} 100 \mathrm{~g}^{-1}\right)$ & $4,80 \pm 0,13(2,76)$ & $3,47 \underline{+0,06}(1,71)$ \\
\hline Sacarose $\left({\left.\mathrm{g} 100 \mathrm{~g}^{-1}\right)}\right.$ & $8,40+0,04(0,50)$ & $7,80+0,02(0,20)$ \\
\hline Vitamina C (mg $\left.100 \mathrm{~g}^{-1}\right)$ & $14,68+0,03(0,20)$ & $44,03+0,05(0,11)$ \\
\hline Fibra insolúvel $\left(\mathrm{g} 100 \mathrm{~g}^{-1}\right)$ & $9,04 \underline{+0,10(0,21)}$ & $15,80 \pm 0,02(0,10)$ \\
\hline Pectina (g pectato de cálcio $100 \mathrm{~g}^{-1}$ ) & $0,35 \pm 0,01(1,15)$ & $0,17 \pm 0,01(4,16)$ \\
\hline Acidez titulável (g ác. cítrico $100 \mathrm{~g}^{-1}$ ) & $0,13 \pm 0,00(0,00)$ & $0,26+0,00(0,00)$ \\
\hline Sólidos solúveis $\left({ }^{\circ}\right.$ Brix $)$ & $16,73 \pm 0,08(0,50)$ & $13,33 \pm 0,15(1,14)$ \\
\hline
\end{tabular}

\footnotetext{
* Valores em base úmida.
} 


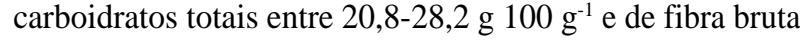
entre 5,8-7,4 g $100 \mathrm{~g}^{-1}$. Esses valores são muito semelhantes aos encontrados neste trabalho, no que diz respeito à umidade e carboidratos totais, porém maiores em se tratando de cinzas, proteínas e lipídios. Os teores de fibras foram bem menores nas variedades indianas em relação à manga 'Haden' brasileira. A diferença da composição química de frutos pode ser explicada pela variação nas condições de cultura (solo, clima, etc.) e no estádio de maturação (SANTOS, 2003).

Segundo Vilas-Boas (1999a), a composição centesimal de um produto exprime, mesmo que seja de forma grosseira, o seu valor nutricional. Os resultados médios da composição centesimal e valor calórico dos tratamentos, com diferentes níveis de casca em substituição à polpa de manga estão apresentados na Figura 1.

Os tratamentos apresentaram umidade variando

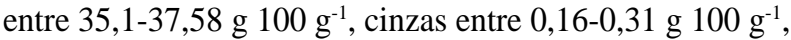

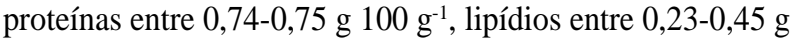
$100 \mathrm{~g}^{-1}$, carboidratos totais entre $60,18-63,42{\mathrm{~g} 100 \mathrm{~g}^{-1} \mathrm{e}}^{-1}$ valor calórico entre 245,79-259,07 kcal. Para Franco (1999), as geléias de polpa de frutas, em geral, possuem ao redor

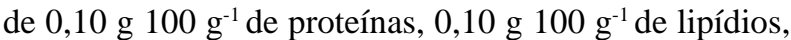

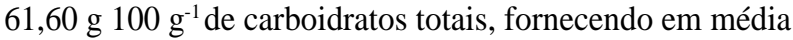
$238 \mathrm{kcal}$, valores abaixo dos encontrados nos tratamentos, excetuando-se os carboidratos totais que foram
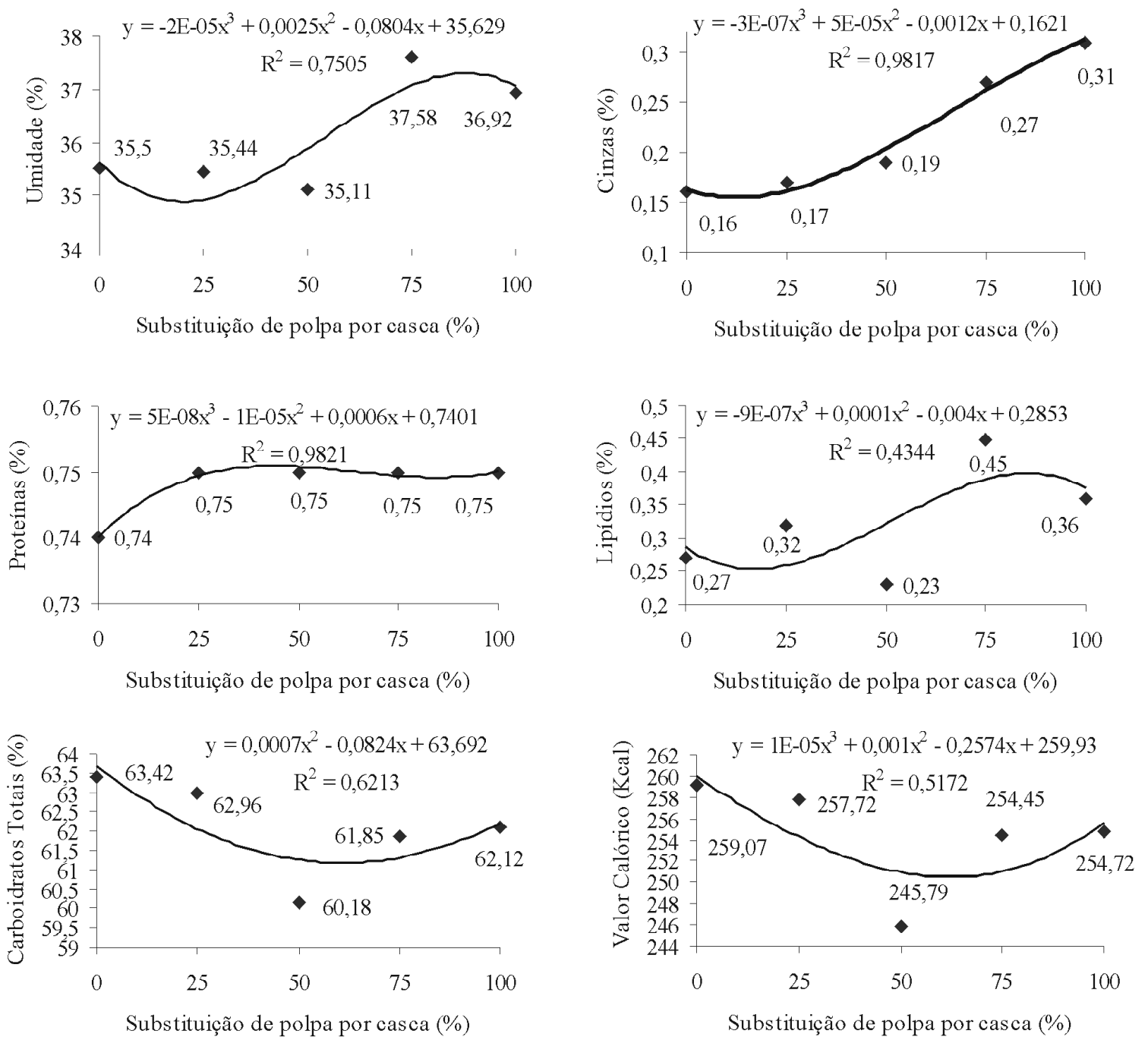

Figura 1 - Composição centesimal (\%) e valor calórico (kcal) dos tratamentos com diferentes níveis de cascas de manga em substituição à polpa. UFG, Goiânia, GO, 2006.

Ciênc. agrotec., Lavras, v. 33, n. 1, p. 177-184, jan./fev., 2009 
semelhantes. A umidade em todos os tratamentos está de acordo com a legislação (BRASIL, 1978), que estipula para geléias de frutas um teor máximo de $38 \% \mathrm{p} / \mathrm{p}$. Os tratamentos controle, com $25 \%$ e $50 \%$ de substituição obtiveram os menores teores de umidade, verificando que o acréscimo de mais de $50 \%$ de casca na formulação, pode diminuir a vida de prateleira, uma vez que o alto teor de umidade facilita o crescimento de fungos filamentosos e leveduras.

O teor de cinzas foi significativamente maior $(0,31$ g $\left.100 \mathrm{~g}^{-1}\right)$ no tratamento com $100 \%$ de substituição e

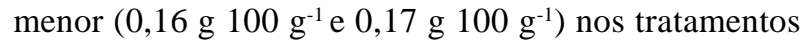
controle e com $25 \%$ de substituição respectivamente. Esse fato pode ser explicado pelo maior teor de cinzas encontrado na casca em relação à polpa (Tabela 2). $\mathrm{O}$ teor

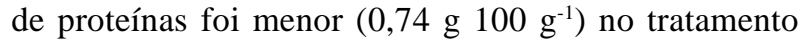
controle, em relação aos demais tratamentos. Com a incorporação da casca na formulação, houve um incremento no teor de proteínas, fato esse explicado pela quantidade maior desse nutriente presente na casca (Tabela 2), embora possa ser notável a diminuição em relação à fruta in natura. Segundo Barcelos \& Ferrua (2003), a diminuição nos teores de proteínas é comum no processamento de alimentos com aplicação de calor em presença de pigmentos, carboidratos, lipídios e alta acidez, fatores presentes na elaboração das geléias. $\mathrm{O}$ teor de lipídios variou entre os tratamentos, o que poderia ser explicado pela desuniformidade de maturação entre as frutas, cujos estádios, conforme escala de Deutsche Gesellschaft Fur Technische Zusammenarbett (1992), encontravam-se entre os níveis quatro e cinco. O teor de lipídios da matéria-prima (Tabela 2) foi reduzido durante o processamento, principalmente naquelas com maiores teores de casca na formulação. Esse fato poderia ser explicado pela oxidação dos lipídios na presença de oxigênio, calor, luz e alta atividade de água (ANDRADE, 2006), presentes durante o processamento das geléias. O comportamento dos carboidratos totais e do valor calórico nos diferentes tratamentos foi semelhante, ou seja, queda com a incorporação de até $50 \%$ de casca (de $63,42 \%$ para $60,18 \%$ e $259,07 \mathrm{kcal}$ para $245,79 \mathrm{kcal}$ respectivamente), seguido de um incremento com a adição de $75 \%$ a $100 \%$ de substituição de casca por polpa $(62,12 \%$ e $254,72 \%$ respectivamente). As geléias de frutas, por conterem um alto teor de carboidratos totais, são altamente calóricas.

Outras análises químicas foram executadas nos diferentes tratamentos (Figura 2).

No tratamento com $100 \%$ de substituição, o teor de fibras insolúveis médio foi maior $\left(1,26 \mathrm{~g} 100 \mathrm{~g}^{-1}\right)$ que nos demais tratamentos, diminuindo com a redução de casca em sua formulação. As fibras insolúveis compreendem os componentes da parede celular dos vegetais, como celulose, hemicelulose e lignina, que não são digeridos pelo organismo humano, assumindo um papel importantíssimo nos movimentos peristálticos e no aumento do bolo fecal, evitando a constipação e anulando o risco de surgimento de hemorróidas e diverticulites (VILAS-BOAS, 1999a).

O teor de vitamina $\mathrm{C}$ foi de $2,5 \mathrm{mg} 100 \mathrm{~g}^{-1}$, em todos os tratamentos. Com o processamento da manga, ocorreram perdas consideráveis dessa vitamina (Tabela 2). A vitamina C, segundo Vilas-Boas (1999b), é a vitamina que degrada mais facilmente, aumentando sua estabilidade em meio ácido e na ausência de luz, oxigênio e calor, fatores presentes no processamento de geléias. Ainda assim, o consumo puro, em bolachas, bolos e/ou tortas, de $50 \mathrm{~g}$ dos produtos obtidos nesse trabalho representa $2 \%$ da ingestão diária recomendada para adultos, cujo valor é de $60 \mathrm{mg}$ de vitamina C (BRASIL, 2006).

Os açúcares totais foram semelhantes nos tratamentos com $75 \%$ e $100 \%$ de substituição $(60,30 \mathrm{~g}$ $100 \mathrm{~g}^{-1}$ e 60,23 g $100 \mathrm{~g}^{-1}$ respectivamente), diferindo dos demais. O menor teor $\left(57,43\right.$ g. $\left.100 \mathrm{~g}^{-1}\right)$ foi encontrado no

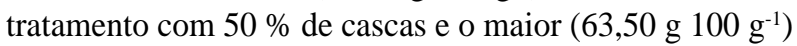
no controle. Durante a cocção da geléia, a sacarose sofre, em meio ácido, um processo de inversão que a transforma parcial ou totalmente em glicose e frutose. Esse fenômeno é necessário para evitar a cristalização do produto, que pode ocorrer durante o armazenamento (LOPES, 1985). No tratamento controle observou-se que ocorreu a conversão total da sacarose em açúcares redutores, que diminuiu à medida que se incorporou maior quantidade de cascas na formulação das geléias. Notou-se também que, quanto maior foi o percentual de açúcares redutores nos tratamentos, menor foi o porcentual de sacarose.

De acordo com a Anvisa (BRASIL, 1978), o teor mínimo de sólidos solúveis em geléias deve ser de $62 \%$ $\mathrm{p} / \mathrm{p}$. Não houve diferença entre os tratamentos, que variaram dentro dos valores exigidos pela legislação. Com o aumento da incorporação de cascas de manga na formulação, que tem uma maior quantidade de ácido cítrico em relação à polpa (Tabela 2 ), se reduziu a quantidade necessária desse na fabricação de geléias (Tabela 1). O tratamento com $100 \%$ de substituição

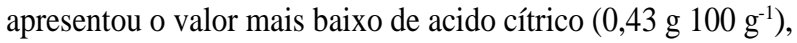
sendo que o maior valor foi encontrado no tratamento controle $\left(0,90 \mathrm{~g} .100 \mathrm{~g}^{-1}\right)$. 

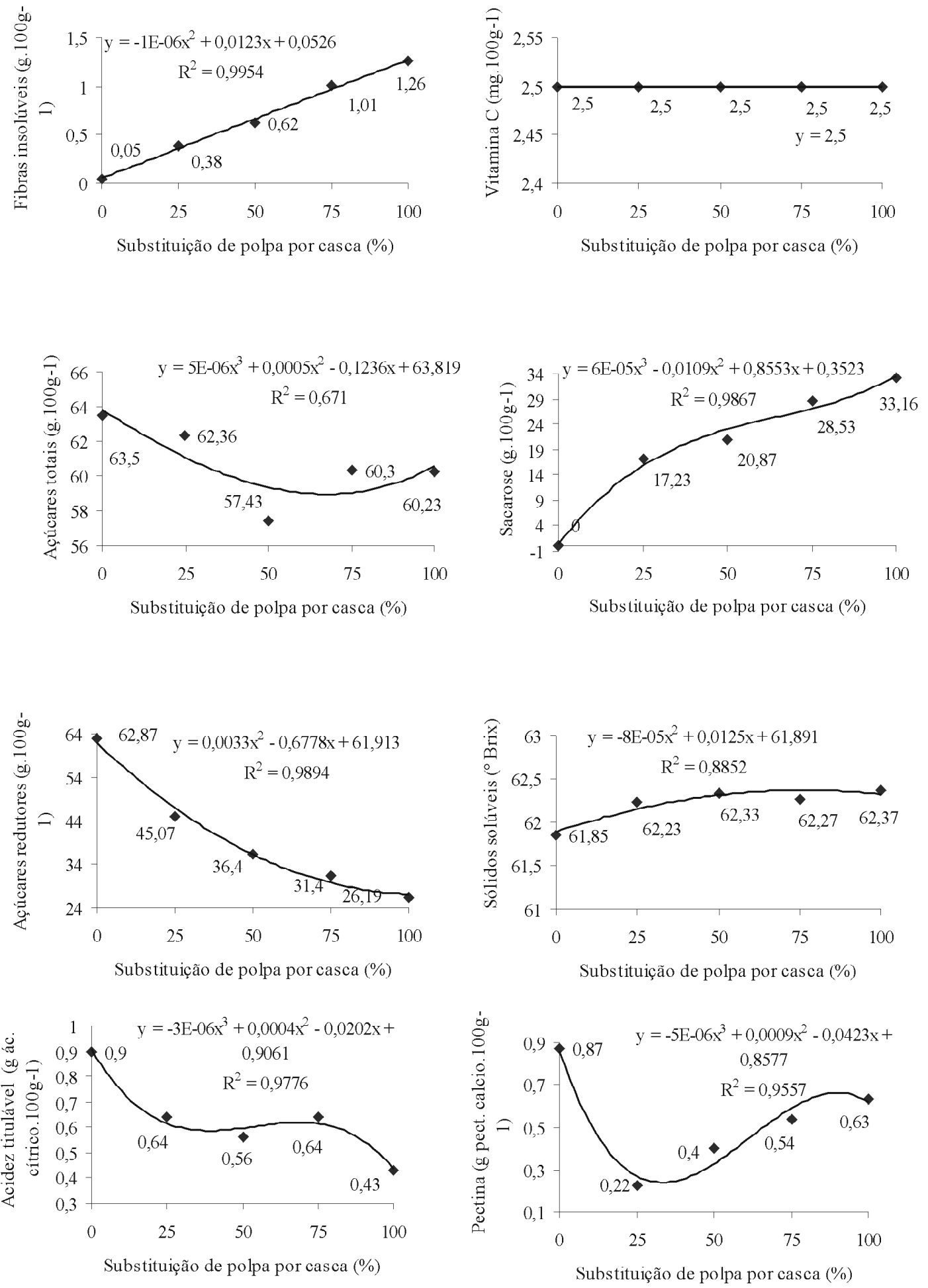

Figura 2 - Características químicas dos tratamentos com diferentes níveis de cascas de manga em substituição à polpa. UFG, Goiânia, GO, 2006. 
A pectina também é um importante fator na formação do gel, fechando o tripé da estrutura da geléia. As frutas destinadas à fabricação de geléias devem-se encontrar em seu estádio de maturação ótimo, quando apresenta seu melhor sabor, cor e aroma. Porém, nesse momento, são pobres em pectinas por sofrerem a ação de enzimas pécticas, durante o amadurecimento. Neste estudo, o teor de pectina, tanto na polpa quanto na casca da manga madura foram insuficientes para a formação do gel, fato esse que explica a adição de pectina cítrica comercial na elaboração das geléias (Tabela 1). $\mathrm{O}$ tratamento controle

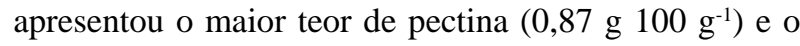
tratamento com $25 \%$ de substituição o menor $(0,22$ g 100 $\left.\mathrm{g}^{-1}\right)$, o que sugere uma maior quebra da molécula de pectina em presença de ácido e calor (JACKIX, 1988).

\section{CONCLUSÕES}

As cascas possuem maiores teores de proteínas, cinzas, lipídios, carboidratos totais, fibras insolúveis, vitamina $\mathrm{C}$ e acidez titulável, e menores teores de umidade, açúcares totais, açúcares redutores, sacarose e pectina em relação à polpa da manga Haden.

A substituição parcial ou total de polpa por cascas de manga Haden, na formulação melhora o valor nutricional e funcional das geléias, apesar da diminuição do valor calórico, com benefícios econômicos e ambientais.

\section{AGRADECIMENTOS}

Ao CNPq, pela concessão da bolsa de doutoramento.

\section{REFERÊNCIAS BIBLIOGRÁFICAS}

AJILA, C. M.; BHAT, S. G.; PRASADA RAO, U. J. S. Valuable components of raw and ripe peels from two Indian mango varieties. Journal of Agricultural and Food Chemistry, Washington, doi:10.1016/j.foodchem.2006.06.036, 2006.

ANDRADE, E. C. B. Análise de alimentos: uma visão química da nutrição. São Paulo: Varela, 2006. 238 p.

ARAUJO, J. L. P. O cultivo da mangueira. Petrolina: Embrapa Semi-Árido, 2004. 28 p. (Sistema de produção, 2).

ASSOCIATION OF THE AGRICULTURAL CHEMISTS. Official methods of the Association of the Agricultural Chemists. 2. ed. Washington, DC, 1995. v. 2.

BARCELOS, M. F. B.; FERRUA, F. Q. Frutas e hortaliças processadas: métodos de conservação e efeitos no valor nutritivo. Lavras: UFLA/FAEPE, 2003. 71 p.
BEYTHIEN, A.; DIEMAIR, W. Laboratoriumsbuch für der lebensmittelchemiker. Leipzig: Verlag von Theodor Steinkopff, 1963. 29 p.

BLIGH, E. G.; DYER, W. J. A rapid method of lipid extraction and Purification. Canadian Journal Biochemistry Physiology, Toronto, v. 37, n. 8, p. 911-917, 1959.

BRASIL. Ministério da Saúde. Agência Nacional de Vigilância Sanitária. Resolução n. 12 do CNNPA. Comissão Nacional de Normas e Padrões para Alimentos, de 24 de julho de 1978. 1978. Disponível em: <http// LWww.anvisa.govip. Acesso em: 4 dez. 2006.

BRASIL. Ministério da Saúde. Secretaria de Vigilância Sanitária. Portaria n. 33, de 13 de janeiro de 1998. Adota valores para as ingestões diárias recomendadas (IDR) de vitaminas, minerais e proteínas. Diário Oficial [da] República Federativa do Brasil, Brasília, 1998. Disponível $\mathrm{em}:\langle\mathrm{http} / /$ :Www.anvisa.gov $\rangle$. Acesso em: 4 dez. 2006.

BRASIL. Ministério da Saúde. Agência Nacional de Vigilância Sanitária. Métodos físico-químicos para análises de alimentos. Brasília, DF, 2005. 1018 p.

CHITARRA, M. I. F.; CHITARRA, A. B. Pós-colheita de frutos e hortaliças: fisiologia e manuseio. 2. ed. Lavras: UFLA, 2005. $783 \mathrm{p}$.

DEUTSCHE GESELLSCHAFT FUR TECHNISCHE ZUSAMMENARBETT. Manual de exportacion: frutas tropicales y hortalizas. Eschborn: Republica Federal de Alemania, 1992. 34 p.

DUBOIS, M. K. A.; GILLES, H. J. K.; REBERS, P. A.; SMITH, F. Colorimetric method for determination of sugars and related substances Analytical Chemistry, Minnesota, v. 28, n. 3, p. 350-55, mar. 1956.

FERRAZ, M. A.; SILVA, C. A. B.; VILELA, P. S. Programa de desenvolvimento da fruticultura no Estado de Minas Gerais: caracterização da agroindústria de frutas no Estado de Minas Gerais. Belo Horizonte: Fapemig, 2002. 17 p.

FRANCO, G. Tabela de composição de alimentos. 9. ed. São Paulo: Atheneu, 1999. 130 p.

GONÇALVES, N. B. Caracterização física e química dos frutos de cultivares de mangueira (Mangifera indica L.). Ciência e Agrotecnologia, Lavras, v. 22, n. 1, p. 72-78, jan./mar. 1998. 
JACKIX, M. H. Doces, geléias e frutas em calda: teórico e prático. Campinas: Ícone, 1988. 148 p.

LESS, L. Manual de análises de alimentos. Zaragoza: Acribia, 1969. 248 p.

LOPES, R. L. T. Manual para fabricação de geléias. Belo Horizonte: Fundação Centro Tecnológico de Minas Gerais, 1985. $17 \mathrm{p}$.

MILLER, G. L. Use of dinitrosalicylic acid reagent for determination of reducing sugar. Analytical Chemistry, Washington, v. 31, n. 4, p. 426, 1959.

MIRANDA, L. C. G.; BATTISTI, C. R. Práticas de química bromatológica. Viçosa: UFV, 2001. 30 p.

SANTOS, C. N. P. Elaboração de um estruturado de polpa de manga (Mangifera indica L. cv Tommy Atkins) parcialmente desidratada por osmose. 2003. $79 \mathrm{f}$. Dissertação (Mestrado em Tecnologia de Alimentos) Universidade Estadual de Campinas, Campinas, 2003.
SAS INSTITUTE. The SAS system for Windows. Version 6.12. Carry, 1996. CD-ROM.

SILVA, R. N.; MONTEIRO, V. N.; ALCANFOR, J. D. X.; ASSIS, E. M.; ASQUIERI, E. R. Comparação de métodos para a determinação de açúcares redutores e totais em mel. Ciências e Tecnologia de Alimentos, Campinas, v. 23, n. 3, p. 337-341, 2003.

UNITED STATE DEPARTMENT OF AGRICULTURE. Nutrient Database for Standard Reference. Composition of foods raw, processed, prepared. Betsville, 1999. (Release, 13).

VILAS-BOAS, E. V. B. Avaliação nutricional dos alimentos. Lavras: UFLA/FAEPE, 1999a. 51 p.

VILAS-BOAS, E. V. B. Alimentos e nutrientes. Lavras: UFLA/FAEPE, 1999b. 74 p.

WILSON, E. D.; SANTOS, A. C.; VIEIRA, E. C. Energia. In: OLIVEIRA, J. E. D.; SANTOS, A. C.; WILSON, E. D. Nutrição básica. São Paulo: Savier, 1982. p. 80. 